\title{
Conjunctival Chemosis Caused by Exposure of the Lacrimal Caruncle: A Case Report
}

\author{
Akinori Baba $^{a}$ Hiromichi Matsuda $^{b}$ Takuya Shiba $^{b}$ \\ Yasuhiro Takahashic ${ }^{c}$ Hiroshi Tsuneoka ${ }^{a}$ \\ ${ }^{a}$ Department of Ophthalmology, The Jikei University School of Medicine, Tokyo, Japan; \\ ${ }^{b}$ Department of Ophthalmology, Daisan Hospital, The Jikei University School of Medicine, \\ Komae, Japan; 'Departments of Oculoplastic, Orbital and Lacrimal Surgery, Aichi Medical \\ University Hospital, Nagakute, Japan
}

\section{Keywords}

Conjunctival chemosis $\cdot$ Lacrimal caruncle $\cdot$ Exposure $\cdot$ Debulking

\begin{abstract}
An 84-year-old woman presented with a 3-month history of conjunctival chemosis in the left eye. At the first examination, the chemosis neighbored the lacrimal caruncle and was localized in the inferomedial region of the conjunctiva. During eyelid closure, only the left lacrimal caruncle was exposed. One month later, the chemosis further extended to the inferolateral region. We debulked the lacrimal caruncle to prevent the exposure of the caruncle. One month after the surgery, conjunctival chemosis had resolved completely. At the postoperative 6-month follow-up, the patient showed no recurrence of chemosis.
\end{abstract}

(C) 2017 The Author(s)

Published by S. Karger AG, Basel

\section{Introduction}

Conjunctival chemosis is characterized by a visible swelling of the conjunctiva. Conjunctival desiccation by ocular surface exposure is one of the major causes of conjunctival chemosis [1, 2], although a variety of ocular and systemic diseases can induce conjunctival che- 
Baba et al:: Conjunctival Chemosis Caused by Exposure of the Lacrimal Caruncle: A Case Report

mosis [3]. However, there has been no report of a conjunctival chemosis caused by exposure of the lacrimal caruncle only.

In the present study, we report a patient with conjunctival chemosis due to exposure of the lacrimal caruncle, who was successfully treated by debulking the lacrimal caruncle.

\section{Case Presentation}

An 84-year-old woman presented with a 3-month history of conjunctival chemosis in the left eye. She suffered from irritation, injection, and foreign body sensation in the left eye. Before referral to us, the patient had received topical eye drops for 3 months, such as $0.1 \%$ betamethasone, $0.1 \%$ sodium hyaluronate, and $1.5 \%$ levofloxacin, but showed no improvement. The patient had no past history of seventh cranial nerve palsy, thyroid disease, nephritis, congestive heart failure, or hypoproteinemia [2].

At the first examination, the chemosis neighbored the lacrimal caruncle and was localized in the inferomedial region of the conjunctiva in the left eye (Fig. 1a). The caruncle was partially exposed without exposure of the conjunctiva during eyelid closure (Fig. 1b). Drying was observed macroscopically on the surface of the lacrimal caruncle. Ophthalmoscopic examination did not reveal noticeable findings, including allergic conjunctivitis, corneal ulcer, dry eye, uveitis, panophthalmitis, and angle closure glaucoma [2]. Palpebral fissure height and Hertel exophthalmometry measurements were within normal limits. The patient did not show lid lag. Computed tomography of the orbit demonstrated no manifest involvement related to Graves orbitopathy, an orbital tumor, and orbital cellulitis [2]. The diameter of the superior ophthalmic vein was within normal limits [4]. Hematological analysis showed that free T3, free T4, thyroid-stimulating hormone, creatinine, blood urea nitrogen, total protein, and albumin were within normal limits. Although we obtained a partial resolution just after a puncture of the chemosis with a 23-gauge needle, the lesion soon recurred, and then, the chemosis was found to deteriorate, further extending to the inferolateral region.

Because exposure of the lacrimal caruncle during eyelid closure was thought to play a role in aggravating chemosis, the exposed lacrimal caruncle was debulked 1 month after the first examination. After infiltrating with $1 \%$ lidocaine with 1:100,000 epinephrine, the caruncular surface was cut vertically. Tissue just beneath the surface was dissected from the surrounding structures and removed until the caruncle was not exposed during eyelid closure. Incision of the area of the conjunctiva with chemosis was not performed at all during this procedure. The wound was closed with 9-0 virgin silk sutures. The patient was subsequently treated with $0.1 \%$ topical fluorometholone and $1.5 \%$ levofloxacin eye drops for 2 weeks.

Two weeks postoperatively, the chemosis had partially improved, and at the 1-month follow-up, the patient had a marked reduction of symptoms and the chemosis had completely resolved (Fig. 1c, d). Chemosis had not recurred until the postoperative 6-month follow-up.

\section{Discussion}

This is the first case report of conjunctival chemosis in a patient with exposure of the lacrimal caruncle, which was successfully treated by debulking the lacrimal caruncle. Desiccation of mucous tissues causes endothelial dysfunction, fluid extravasation, and edema [1]. 
Baba et al.: Conjunctival Chemosis Caused by Exposure of the Lacrimal Caruncle: A Case Report

The lacrimal caruncle has a nonkeratinized mucosal epithelial surface [5], suggesting that exposure of the lacrimal caruncle solely can cause conjunctival chemosis.

Conjunctival chemosis is caused by a variety of ocular and systemic diseases, including conjunctivitis, corneal ulcer, uveitis, panophthalmitis, acute angle closure glaucoma, orbital venous stasis, orbital cellulitis, nephritis, congestive heart failure, and hypoproteinemia [3]. However, these diseases were excluded by the patient's past history and by the results of the ophthalmoscopic examination, computed tomography, and blood tests. Inflammation of the excised lacrimal caruncle was not histopathologically proven; however, localized chemosis around the lacrimal caruncle and improvement of chemosis after debulking the lacrimal caruncle implied lacrimal caruncular desiccation by ocular surface exposure as the main cause of conjunctival chemosis in this patient.

The conjunctival chemosis improved after debulking the lacrimal caruncle in this patient with no resolution by prolonged use of lubricant and steroid eye drops. Although conservative management is the common management for conjunctival chemosis, eye drops cannot spread over the projecting lacrimal caruncle located medial to the lacrimal puncta and lake [6]. Intractable conjunctival chemosis may implicate an indication of surgical treatments, such as conjunctivoplasty [7], perilimbal needle manipulation [8], and high-frequency radiowave [9]; however, these procedures are incompatible with the etiology in this patient.

In conclusion, we present a case of conjunctival chemosis by exposure of the lacrimal caruncle, which was successfully treated by debulking the lacrimal caruncle. Although the reporting of only a single case was a limitation of our study, this case indicates that desiccation of the lacrimal caruncle is a possible etiology of localized conjunctival chemosis.

\section{Statement of Ethics}

This study adheres to the tenets of the 1964 Declaration of Helsinki. Written informed consent was obtained from the patient for publication of this case report and any accompanying images.

\section{Disclosure Statement}

The authors declare no conflicts of interest.

\section{References}

1 Weinfeld AB, Burke R, Codner MA: The comprehensive management of chemosis following cosmetic lower blepharoplasty. Plast Reconstr Surg 2008;122:579-586.

2 Takahashi Y, Kang H, Kakizaki H: Lower incidence of chemosis with the Berke incision approach versus the swinging eyelid approach after deep lateral orbital wall decompression. J Plast Surg Hand Surg 2016;50:15-18.

3 Nema H, Nema N: Diseases of the conjunctiva; in Nema H, Nema N (eds): Textbook of Ophthalmology, ed 6. New Delhi, Jaypee Brothers Medial Publishers Ltd., 2012, pp 114.

4 Nugent RA, Belkin RI, Neigel JM, Rootman J, Robertson WD, Spinelli J, Graeb DA: Graves orbitopathy: correlation of CT and clinical findings. Radiology 1990;177:675-682.

5 Cole HP, Wesley RE: Conjunctiva: structure and function; in Bosniak S (ed): Principles of Ophthalmic Plastic and Reconstructive Surgery. Philadelphia, Saunders, 1996, pp 159-163.

6 Whitnall SE: Anatomy of the Human Orbit and Accessory Organs of Vision, ed 2 (reprint). New York, Robert E Krieger Publishing Company Inc., 1979, pp 164-165. 


\section{Case Reports in Ophthalmology}

\begin{tabular}{l|l}
\hline Case Rep Ophthalmol 2017;8:120-123 \\
\hline DOI: 10.1159/000457787 & $\begin{array}{l}\text { @ 2017 The Author(s). Published by S. Karger AG, Basel } \\
\text { www.karger.com/cop }\end{array}$ \\
\hline
\end{tabular}

Baba et al: Conjunctival Chemosis Caused by Exposure of the Lacrimal Caruncle: A Case Report

7 Thakker MM, Tarbet KJ, Sires BS: Postoperative chemosis after cosmetic eyelid surgery: surgical management with conjunctivoplasty. Arch Facial Plast Surg 2005;7:185-188.

-8 Cheng JH, Lu DW: Perilimbal needle manipulation of conjunctival chemosis after cosmetic lower eyelid blepharoplasty. Ophthal Plast Reconstr Surg 2007;23:167-169.

-9 Woo KI, Choi CY: High-frequency radiowave electrosurgery for persistent conjunctival chemosis following cosmetic blepharoplasty. Plast Reconstr Surg 2014;133:1336-1342.
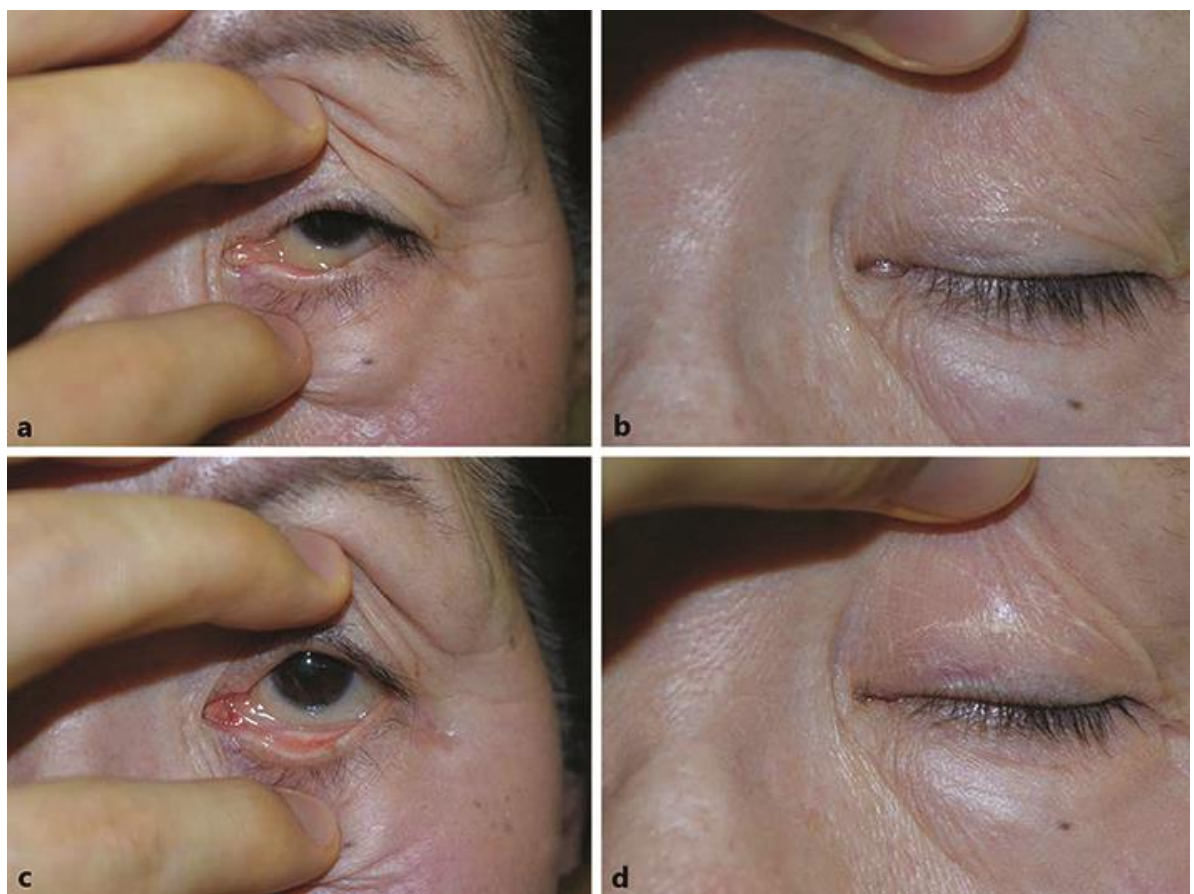

Fig. 1. Patient photographs. a Conjunctival chemosis is shown adjacent to the lacrimal caruncle at the first examination. b The lacrimal caruncle is partially observed preoperatively during eyelid closure. c No conjunctival chemosis is observed 1 month postoperatively. $\mathbf{d}$ Postoperatively, the lacrimal caruncle is hidden during eyelid closure. 